\title{
A Power Electronic Controlled Dump Load with Negligible Harmonics for Accurate Loading Used in Testing Small Wind Turbines
}

\author{
Christian Klumpner ${ }^{1} \quad$ Baydu $\mathrm{Al}^{2} \quad$ David Hann ${ }^{2}$ \\ ${ }^{1}$ Division of Electrical Systems and Optics $\quad{ }^{2}$ Division of Energy and Sustainability \\ Faculty of Engineering, University of Nottingham \\ University Park, Nottingham, NG7 2RD, United Kingdom \\ Email: klumpner@ieee.org
}

\begin{abstract}
Permanent magnet synchronous generators (PMSG) are at the core of small scale wind power generators manufactured by a wide range of manufacturers in different configurations: vertical or horizontal axis blades, with various geometries and aerodynamics of the blades; by installing these small scale wind turbines in very large numbers at household levels, it is expected that these will make a positive contribution to the increase of renewable energy generation, reducing the use of fossil fuels that are blamed for climate change. However, a proper evaluation of the technical specification of these small scale wind generators in various weather conditions is necessary in order to assess the full potential of benefits. This paper reports on the implementation and testing of a power electronic dump load that allows continuously adjustable loading of a PMSG with sinusoidal currents and have the capability to self synchronize to its frequency/speed whilst avoiding transient/loosing of synchronism.
\end{abstract}

\section{INTRODUCTION}

When testing the performance of electrical generators, a variable electrical load that can be conveniently adjusted is always necessary. Other applications would require the installation of an electrical load to be used when the main equipment or the power network that was sinking the generated power fails and typical examples are generators used in wind turbines [1]-[4], automotive [5] or a dissipative load to be used in conjunction to the main power converter used to facilitate the energy transfer (referred to as clamp circuits [6] or braking choppers). In the latter case, a less wide adjustability of the electric load is needed. The energy dissipative element can be a resistor or even a power semiconductor (a Zenner diode or a transistor controlled in the linear region), but careful consideration needs to be taken when designing this circuit to accommodate safe dissipation of the incoming energy by providing sufficient cooling.

One important aspect that sometimes is omitted is the harmonic impact that this load can have on the main system. If the load consists of only resistors (no switch-mode power electronics) as suggested in Fig. 1a, there is a guaranteed linear behavior with no negative harmonic impact; however, in case the system tested is a multiphase AC generator, a more complex mechanical arrangement to adjust all phase load resistors simultaneously is needed. In case added functionality (advanced/fast control) is needed, the use of solid state switching devices such as thyristors or transistors, in conjunction to fixed resistors is necessary. The typical circuits used in such situations are briefly described below:

1) Thysistor based dump load: the topology consist of a pair of antiparalel thysistors or a triac connected in series to a fixed resistor [1]-[3], as shown in Fig. 1b. By controlling the firing angle of the thyristors, it can be varied the voltage delivered to the resistors which changes then the current drawn from the main circuit by the dump load. The advantage is that the circuit seems quite simple; however it needs two controlled devices per phase but the main drawback is the large amount of low order harmonics, with a harmonic profile highly dependent on the firing angle that is generated.

2) Diode bridge embedded braking chopper: this circuit consists of a single/three phase diode bridge with a resistor connected in series with a forced commutated switch (Fig. 1cd). A freewheeling diode is sometimes necessary to be connected in parallel to the resistor to compensate for its inductance (supposingly the braking resistor needs to be placed further away to avoid heating up the power devices/electrolytic capacitors). In the literature, many variations of this circuit can be found [3]-[8]. In [3]-[4], a capacitor is connected in the DC-link to decouple the influence of switching current ripple on the circuit inductance, as shown in Fig. 1c. This makes the circuit to behave as a capacitivelly smoothed rectifiers on the AC side, generating therefore large level of low order harmonics $\left(5^{\text {th }}\right.$, $7^{\text {th }}, 11^{\text {th }}, 13^{\text {th }}$ etc), which is higher when the $\mathrm{AC}$ side inductance is low; the equivalent THD will tend to vary widely at the boundary between continuous and discontinuous current conduction mode. In [7], there is no DC-link capacitance but the use of AC side capacitive decoupling was suggested as capacitive decoupling at the dump load's diode bridge AC inputs is essential to limit the amount of overvoltage generated during current pulse transitions. In this situation, the harmonic content of the AC side current is further improved, as this type of dump load illustrated in Fig. 1d would behave quite similar to a inductively smoothed diode rectifier (typical THD $=30 \%$ ). 


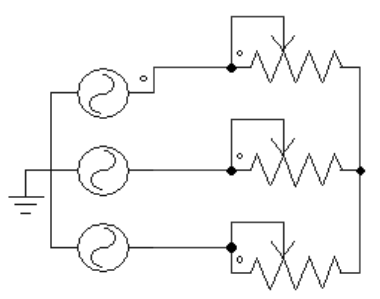

(a)

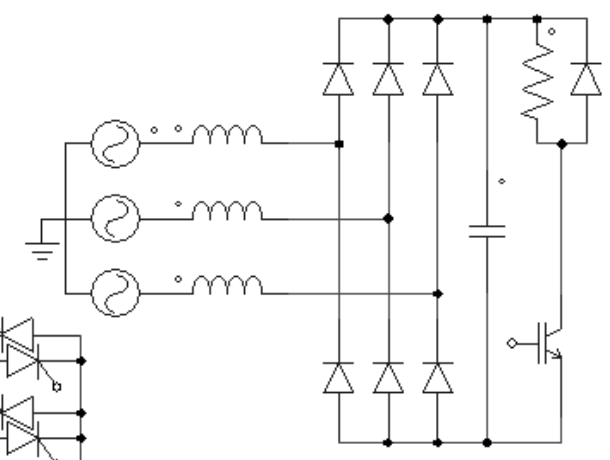

(c)

(b)

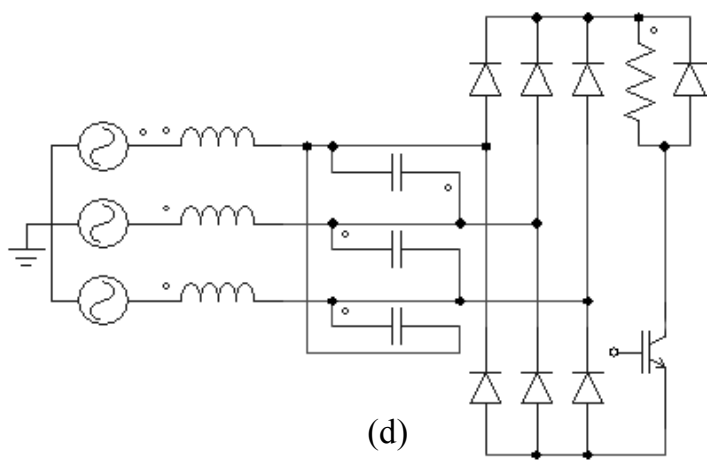

Fig. 1. Various ways to implement three-phase dump loads: a) using adjustable rheostats; b) using fixed resistors in conjunction to antiparallel thyristors; c) capacitivelly smoothed rectifier with DC-link connected braking chopper; d) diode bridge embedded braking chopper with AC capacitive decoupling.

In [8], three individual single phase dump loads are proposed to be used; Even though the number of semiconductor devices increases to 12 diodes and 3 transistors, the circuit allows independent adjustment of the equivalent dump load resistance in each phase, but more importantly, since connects to only two lines, can always generate a current that is proportional with the voltage between the two lines, therefore potentially sinusoidal.

\section{THE PROPOSED CIRCUIT}

This paper proposes a power electronic adjustable dump load topology shown in Fig. 2 that can be easily upgraded to be digitally controlled to be used in testing a low power PMSG wind turbine. It consists of three fixed resistors sized to be able to draw the maximum/rated generated current, a three phase diode rectifier made of fast recovery diodes and an active switching device (MOSFET/IGBT). Each time the transistor turns on, the positive and the negative rectifier terminals are shortcircuited, meaning a shortcircuit of all three AC inputs, which has an effect of closing the star connection (neutral point) between the three fixed resistors, and the build up of load current. Turning off the power device means that the negative and positive diode bridge are disconnected, which is equivalent to open connections on its AC side, which means that there is no path for the load currents to close (therefore zero current). Adjusting the ontime dutycycle, gives the possibility to adjust the value of the equivalent load resistor per phase. Also, since at each $\mathrm{ON}$ instant, the amplitude of the current passing through the resistors will always be proportional to the phase voltage, if these voltages are sinusoidal, the resistor current, besides having a high frequency content given by the switching action/frequency, will contain also a clear low frequency component equal to the frequency of the voltage, which avoids the generation of any low frequency harmonics. Also, since the circuit passively locks on the PMSG stator voltage, it avoids any of the synchronisation problems associated with synchronous generators. A set of three delta connected capacitors and a set of line inductors (which can be just the stator leakage inductance of the PMSG) are needed on the generator side (other side of the resistors) to smooth the high frequency current pulses and allow only the low frequency component to pass though the generator windings.

Since the phase resistor is connected in the circuit only when the transistor is on, a switching sequence repeated with a frequency much higher than any other dynamic process in this circuit, an average continuous equivalent resistance dependent on the dutycycle facilitated by the presence of the filter capacitors will appear in the circuit:

$$
\mathrm{R}_{\text {equiv }}=\mathrm{R}_{\mathrm{L}} / \mathrm{D}
$$

Where the $\mathrm{D}$ is the dutycycle; when this is $100 \%$, the transistor is fully on and the equivalent phase resistance is equal to the actual value of the resistance. However, when the dutycycle is decreased, the equivalent phase resistance increases at very high values significantly above the physical resistance connected in the circuit.
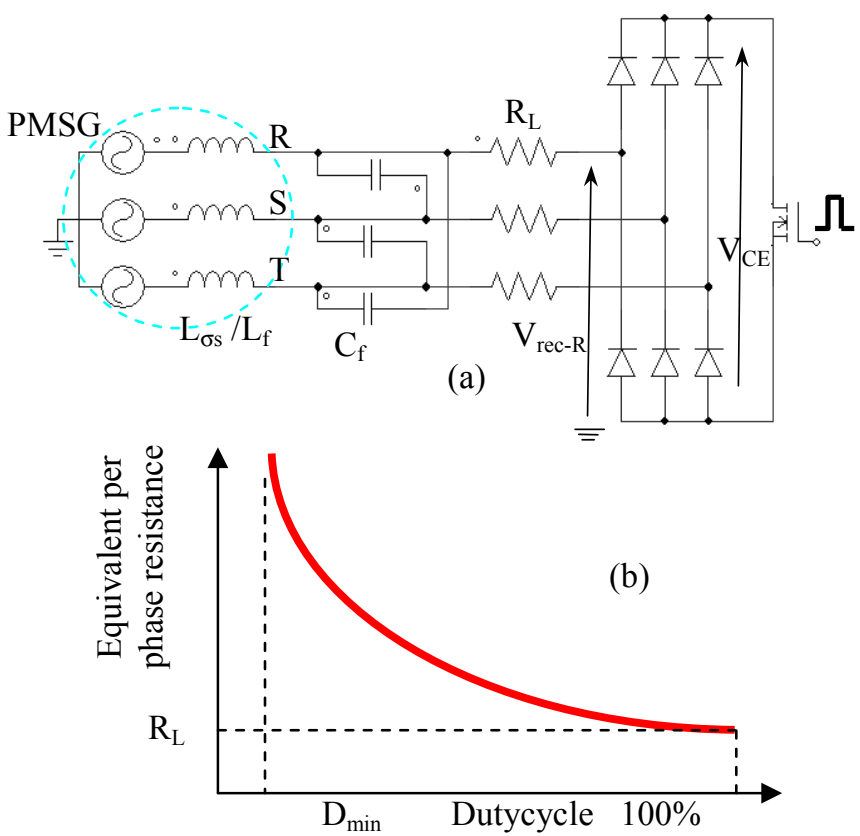

Fig. 2. a) Schematic of the dump load with low harmonic impact; b) equivalent resistance variation versus dutycycle. 
The range of varying the equivalent phase resistance is limited by the range of producing the control pulse dutycycle. Assuming that these limitations are $\mathrm{D}_{\min }$ and $\mathrm{D}_{\max }$, it means that the equivalent phase resistance will vary between $R_{L} / D_{\max }$ and $R_{L} \cdot D_{\max } / D_{\text {min. }}$. For example, if the minimum dutycycle is $10 \%$ and the maximum one is $90 \%$, the variation range of the phase resistance is $1.1 \mathrm{R}_{\mathrm{Lf}}$ to $9 \mathrm{R}_{\mathrm{L}}$. This aspect needs to be considered when deciding the value of the actual circuit resistance in order to accommodate the desired range for the generator loading test.

\section{EXPERIMENTAL RESULTS}

A prototype has been built to allow the loading of a $150 \mathrm{~W}$ vertical wind turbine equipped with a PMSG. The phase rated voltage (at rated speed) is $120 \mathrm{Vrms}$. In order to accommodate the possibility to build sufficient current in the circuit at reduced speed, a smaller phase resistor of $50 \mathrm{Ohm}$ has been used, which in conjunction to a signal generator able to provide dutycycles in the range of $10-90 \%$, resulted in achieving a equivalent phase resistor range of 55-450 $\Omega$.

\section{A. Evaluation of the Power Electronic Dump Load}

Fig. 4 shows the voltage across and the current though the transistor and two of the resulting line-to-line voltages as seen at the input of the diode rectifier. The switch voltage shows a characteristic top envelope for a six pulse rectifier, but highly discontinuous, which is the key in drawing controlled power from all three source lines by using a single switch. The diode bridge line-to-line voltages also experience a sinusoidal envelope which is typical for the transition of the bridge $\mathrm{AC}$ input potential from the neutral of the balanced load resistors $(0 \mathrm{~V}$ when transistor is on), to line potential (transistor is off).
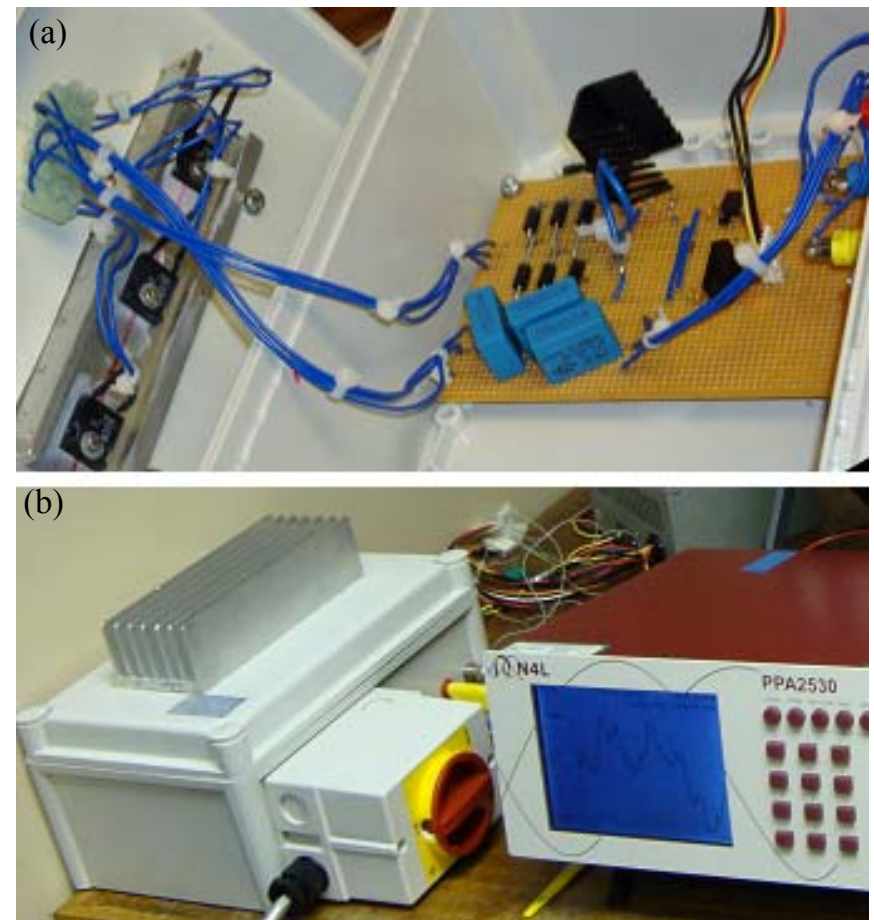

Fig. 3. The experimental setup: a) dump load circuit; b) assembled test rig including dump load and power analyzer.
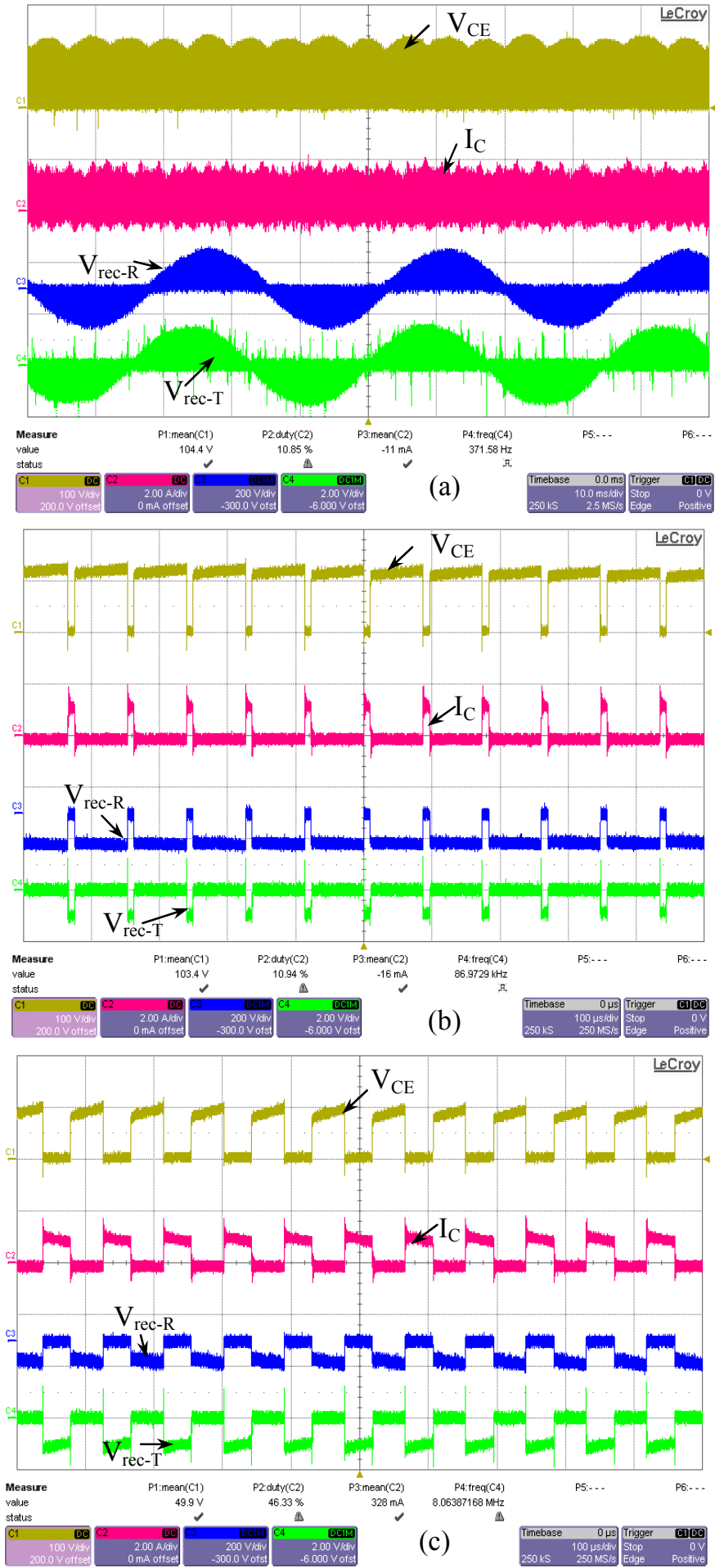

Fig. 4. Experimental results of the voltage across (top) and the current though (second) the dump-load transistor and two of the resulting line-to-line voltages seen at the $\mathrm{AC}$ input of the diode rectifier (third, fourth): a) large time scale overview (10ms/div); b-c) short time $(0.1 \mathrm{~ms} / \mathrm{div})$ switching cycle overview at b) low (10\%) and c) medium (50\%) dutycycles.

The effect of varying the dutycycle on the PMSG line-toline voltages and currents is seen in Fig. 5 where two of each are shown (due to limitations to four available oscilloscope 
channels). The test conditions differ because at low dutycycle the equivalent resistance is high, which means a light load connected to the generator. Since the wind conditions in the wind tunnel are kept constant, this means that the wind turbine speed at light load $\left(\mathrm{I}_{\mathrm{s}-\mathrm{PMSG}}=0.11 \mathrm{~A}\right)$ will be higher which is revealed by the voltage and frequency measurements $(88.8 \mathrm{~V}$ and $29 \mathrm{~Hz})$. Once the equivalent load resistance is decreased by increasing the dutycycle towards $50 \%$ (Fig. $5 \mathrm{~b}$ ), the stator current increases to approx $0.23 \mathrm{~A}$. Higher power delivered to the load makes the PMSG rotational speed to drop which is revealed by a smaller line-to-line voltage and frequency $(82.2 \mathrm{~V}$ and $26.57 \mathrm{~Hz})$.

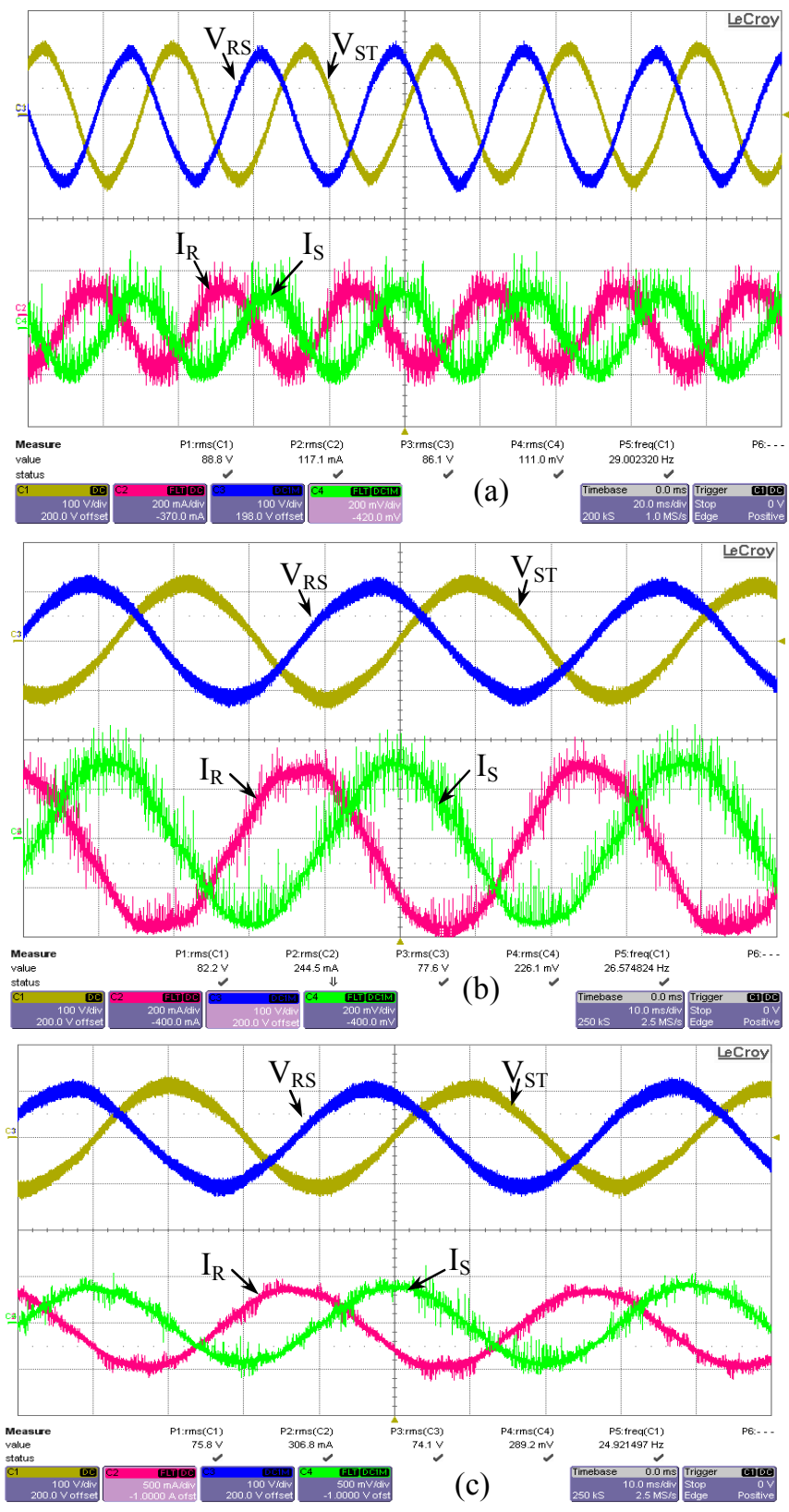

Fig. 5. Experimental waveforms of the generator line-toline voltages (upper) and two line currents (lower) at: a) low $(20 \%)$ b) medium $(50 \%)$ and c) high $(80 \%)$ dutycycles. Time scale: a) $20 \mathrm{~ms} / \mathrm{div}$; b-c) $10 \mathrm{~ms} / \mathrm{div}$.
Near maximum dutycycle, the load resistance further decreased, which causes the increase of the stator currents to approx $0.3 \mathrm{~A}$. The stator voltage and the frequency further decrease to $75.8 \mathrm{~V}$ and $24.9 \mathrm{~Hz}$, reflecting a higher loading of the wind generator.

Fig. 6 shows two transient responses when the dutycycle is varied very quickly from low to high (Fig. 6a) and backwards (Fig. 6b). The load currents change within $200 \mathrm{~ms}$, which is much faster than what could be obtained by handling manually the cursor of a rheostat.

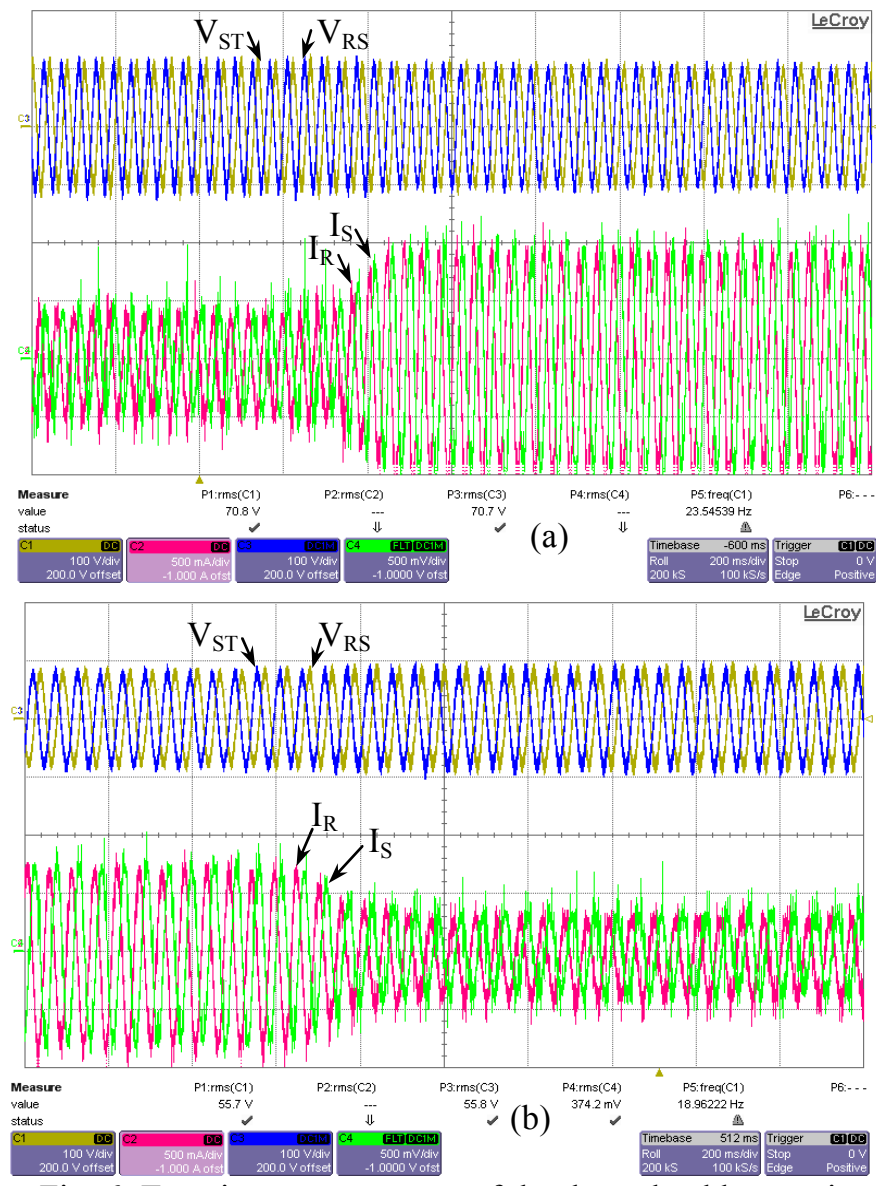

Fig. 6. Transient test response of the dump load by varying the dutycycle: a) from low to high and b) from high to low. Waveforms: two of the stator line-to-line voltages (top waveforms) and generator line currents (bottom waveforms).

\section{B. Evaluation of a Wind Turbine Using the Dump Load}

The loading circuit was tested on a Ropatec vertical axis wind turbine equipped with a PSMG in the Nottingham University Climatic wind tunnel. The assembly is shown in Fig. 7. The performance of the turbine was tested at 5 different wind speeds, between $7-12 \mathrm{~m} / \mathrm{s}$. The turbine wind speed was allowed to settle after each load change for 5 minutes before averages of the electrical power, stator voltage, current and frequency were taken, using the data logging feature of the power analyzer. 


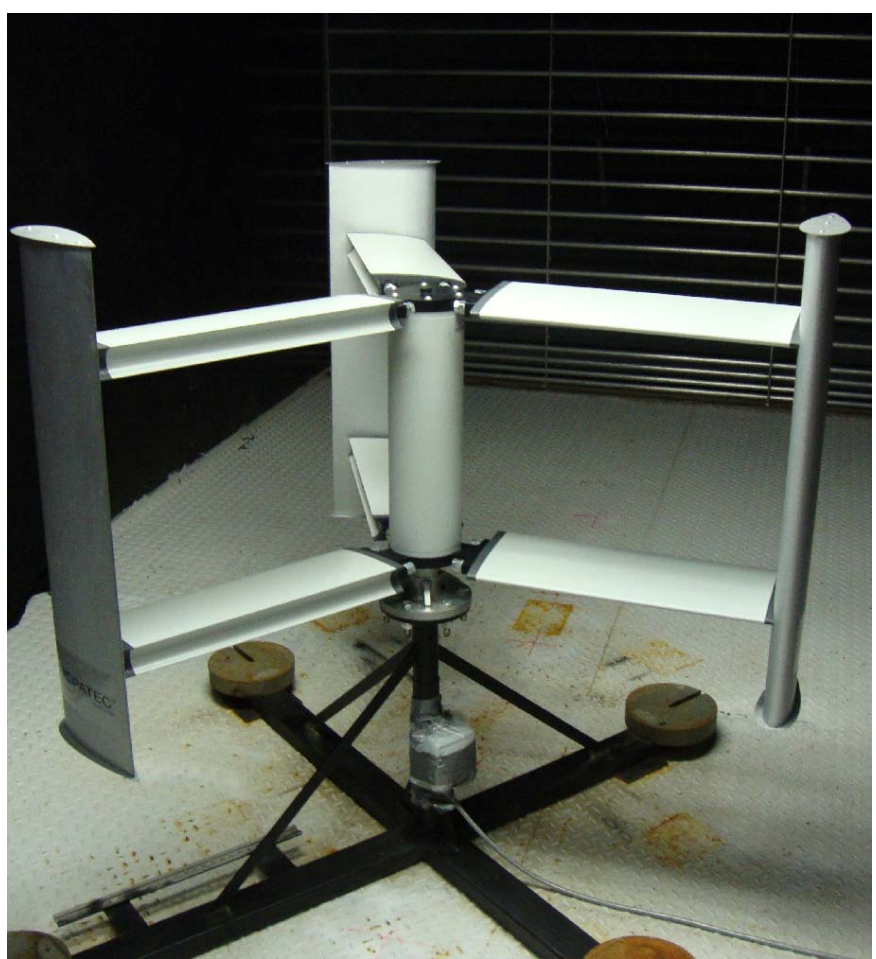

Fig. 7. The Ropatec Vertical axis wind turbine ready for testing in the Nottingham University Climatic wind tunnel.

Fig. 8 shows a 500 seconds data sample of the electrical output power and stator frequency of the wind turbine; the small ripple is caused by the natural variation of the output due to some turbulence in the wind tunnel.

For wind turbines it is important to monitor that the tip speed ration $(\lambda=r \omega / U)$ is kept constant. Fig. 9 shows that the experimentally determined tip speed ratio of the turbine depicted as a function of the inverse of the equivalent load phase resistance and determined at different wind speeds are consistently following a linear trajectory as expected from theory with no significant dispersion, which proves that the load connected to the PMSG does not cause non-linearity and that the measurement system has a low level of noise.

Fig. 10 shows the electrical power as a function of the tipspeed ratio for different wind speeds. It can be noted that the maximum power point always correspond to a tip-speed ratio of 2.7. This is also confirmed in Fig. 11 which shows the power conversion coefficient versus tip-speed ratio (this refers to the electrical power as the measured electrical power did not included the losses in the PMSG) for all the tested wind speeds that peaks at $16 \%$ and has all its points falling consistently on a typically curved trajectory with very little dispersion, confirming again that the optimal tip-speed ratio is about $\lambda=2.7$. It should be noted that in Fig. 11 in order to maintain the maximum tip-speed ratio of 2.7 as the wind speed varies, it was necessary to vary the equivalent phase load resistance between 60 to $90 \mathrm{Ohms}$ to respond to wind changes. Continuous changes in the load are necessary to keep the tip speed ratio above 2, as sudden fluctuations in the wind speed can easily cause the system to stall which means that the power output will drop significantly and a circuit that can quickly, continuously and accurately change the load will be of great use to optimize power output.
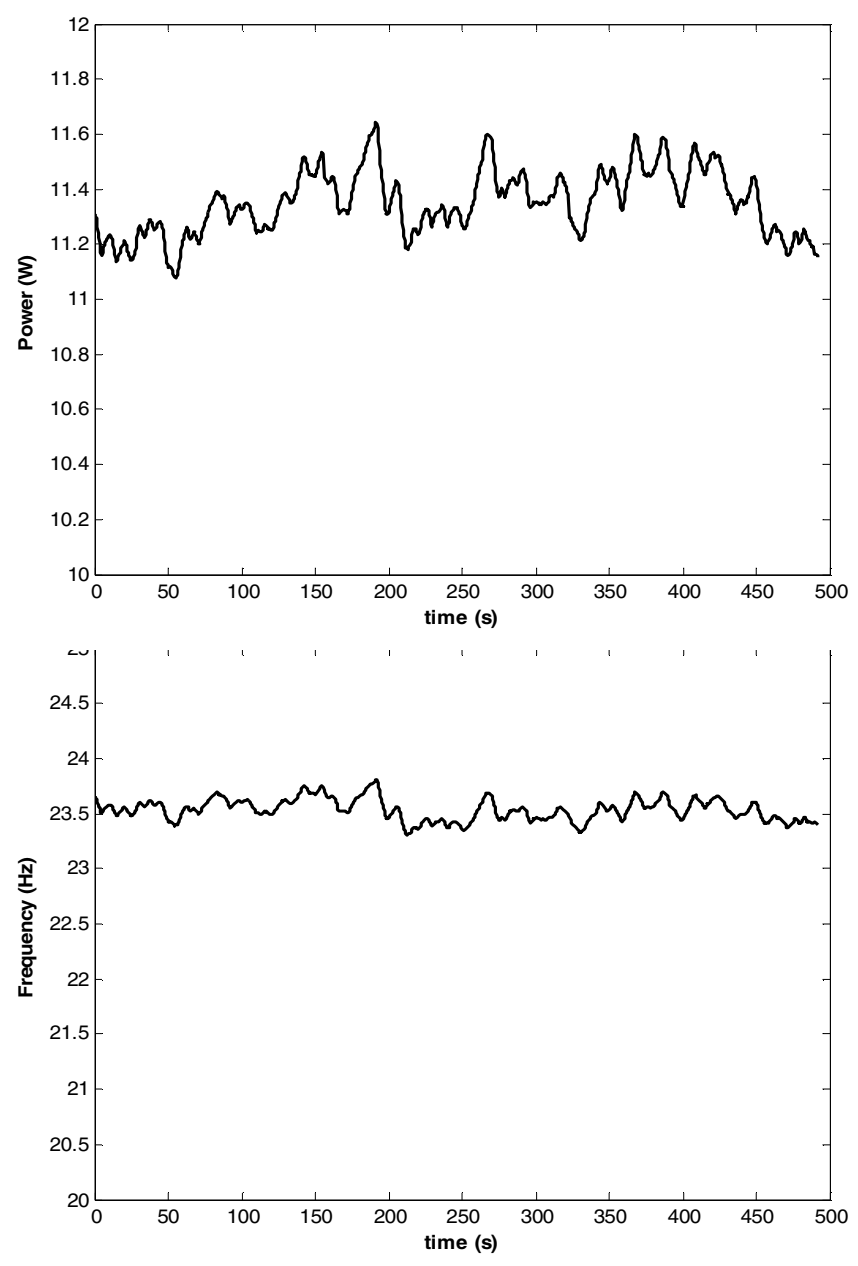

Fig. 8. Segment of data showing the variation of the power and frequency over the averaging period.

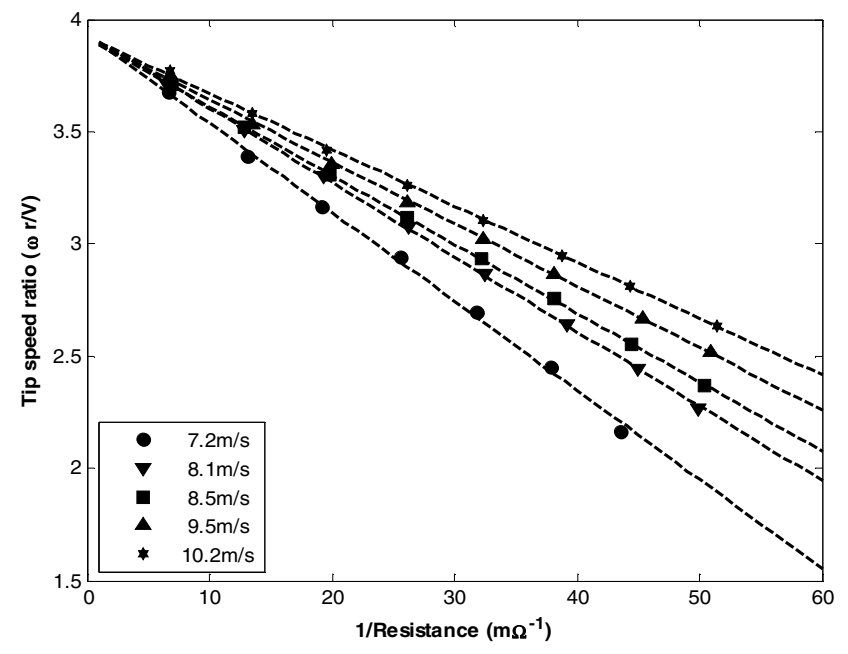

Fig. 9. Variation of the average Tip-Speed ratio with the equivalent per-phase load resistance and wind speed. 


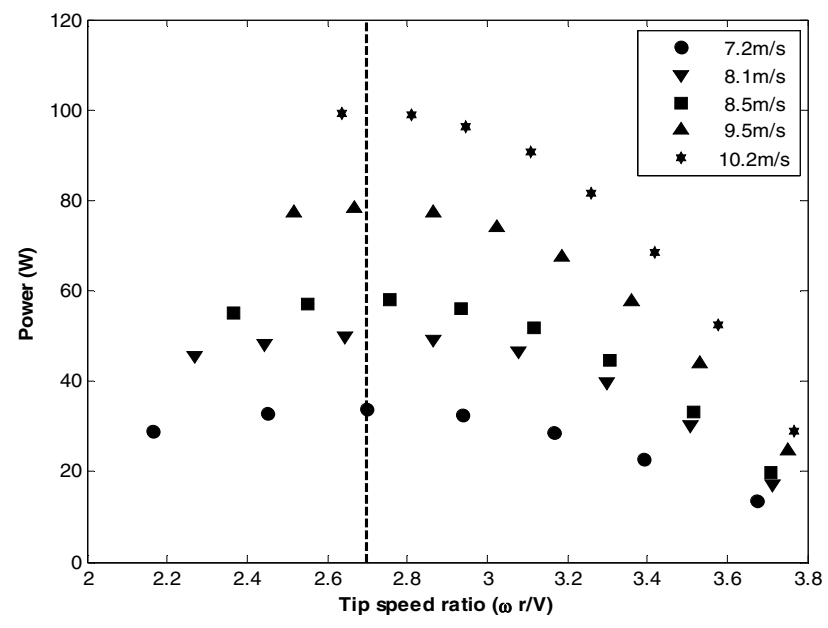

Fig. 10. Variation of the Power output with the Tip-Speed Ratio for different wind speeds.

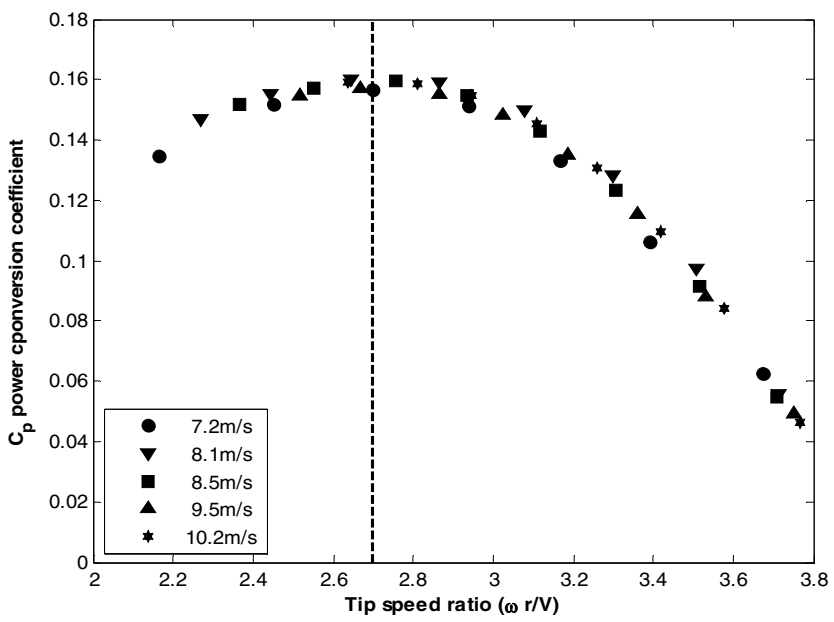

Fig. 11 Variation of the Power conversion coefficient with the tip speed ratio considering all wind speeds tests.

Regarding the performance of the electronic loading system, it can be noticed that all curves show very small dispersion of measured points in respect to the expected curves/envelopes which means that the measurement errors are small and that the efficiency of converting mechanical energy into electrical inside the PMSG remains consistently high, facilitated by the very low content in harmonic currents.

\section{CONCLUSIONS}

In this paper, the application of a power electronic controlled dump load that has low harmonic impact in performing load tests a low power wind generator equipped with a three phase permanent magnet synchronous generator is presented.
The solution fulfilled the following requirements:

- A very cheap and simple design consisting of only a single controlled switch;

- A single point of adjustment for all phase resistors to obtain a symmetrical and continuous adjustment of the phase load resistors;

- A very low harmonic content in the generator stator currents leading to a power factor virtually equal to one at the generator terminals. This was necessary to ensure that the generator losses, which at this moment are not accounted for, vary consistently and marginally with the wind turbine operating point (i.e. changes in the way the dump load operates such as transition from continuous to discontinuous current conduction would typically cause a significant change in the amount/distribution of generator power losses);

- The possibility to easily add in the future a digital controller to automatically adjust the loading in order for the system to identify/implement maximum power point tracking.

This prototype has been successfully employed in determining with very high accuracy the power/rotational speed interrelation with the wind speed in a wind tunnel measurement with the final objective to study the impact of various environmental factors in the turbine behaviour [9]. And having access to an accurate electrical load power measurement system was essential in excluding any unwanted influence in the collected data set.

\section{REFERENCES}

[1] J.R. Bumby, N. Stannard, J. Dominy, N. McLeod, "A permanent magnet generator for small scale wind and water turbines", Proc. of Int. Conf. on Electrical Machines ICEM'08, pp. 1 - 6, 2008.

[2] L.A.C. Lopes, R.G. Almeida, "Wind-driven self-excited induction generator with voltage and frequency regulated by a reduced-rating voltage source inverter", IEEE Trans. on Energy Conversion, Vol. 21, No. 2, pp. 297 - 304, 2006.

[3] T.C.Y.Wang, W. Yang, X. Yuan, R. Teichmann, "A redundant electrical braking system for wind turbine generators" Proc. of European Power Electronics and Apps Conf. EPE'07, pp. 1 - 8, 2007.

[4] B. Singh, S.S. Murthy, S. Gupta, "Analysis and implementation of an electronic load controller for a self-excited induction generator", IEE Proc. of Generation, Transmission and Distribution, Vol. 151, No. 1, pp. $51-60,2004$.

[5] J.D. Dimech, "Standardized automotive load dump testing", Proc. of Symp. on Electromagnetic Compatibility, ISEMC'91, pp. 355-3591, 1991.

[6] C. Klumpner, F. Blaabjerg, "Short term braking capability during power interruptions for integrated matrix converter-motor drives", IEEE Trans. on Power Electronics, Vol.19, No.2, pp.303-311, 2004.

[7] I. Serban, C. Ion, C. Marinescu, M.N. Cirstea, "Electronic Load Controller for Stand-Alone Generating Units with Renewable Energy Sources", IEEE Proc. of Annual Conf. on Industrial Electronics IECON'06, pp. 4309 - 4312, 2006.

[8] I. Serban, C. Marinescu, "A new control method for power quality improvement in island microgrids", IEEE Proc. of Int. Symp. On Industrial Electronics ISIE'08, pp. 2258 - 2263, 2008.

[9] Baydu Al Can, "Effect of rain on wind turbine performance", Nuffield Foundation sponsored Undergraduate research bursary, Ref: URB37068. 